\section{Animals do have rights}

SIR - I believe your leading article, "What rights for animals?" (Nature 306, 522; 1984) contains three important fallacies. First, implicit in the article is the assumption that we do at present put a sufficiently high value on the human right to life and freedom from suffering. While children are still allowed to die of hunger because affluent nations prefer to convert vegetable foods to meat (with around 90 per cent wastage) rather than undertake the difficult task of achieving fair distribution of essentials, this cannot be so.

Second, the article initially claims that retarded humans have rights, while animals do not, because ill-treatment of subnormal humans may lead to similar treatment of humans who are "different" but not "inferior", while ill-treating animals cannot have this effect (because of the clear distinction between animals and humans). It then goes on to say that "wanton" illtreatment of animals (that is, cruelty for fun) is wrong because it corrupts the human values of compassion. However, if this is true, one must accept that some degree of continuity exists between the emotions which govern our behaviour towards human beings and those which occur when we interact with animals. In fact there is a considerable body of evidence which suggests that cruelty towards animals and violence towards humans do have common causes.

If compassion towards animals is not a qualitatively different emotion from compassion towards humans, and since a very great deal remains to be done to remove the injustices which many humans suffer, it can only be a healthy sign that there are people whose "personal compassion outweighs any desire to eat meat". Thus animals could well be judged to have rights on the basis of the arguments which your writer accepts as valid in the case of retarded humans. (Although I do not myself accept that such humans have rights only because being cruel to them might lead to mistreatment of "real" people.)

Third, I think the article assigns an unbalanced degree of importance to certain human states of mind. Clearly there is a moral difference between inflicting suffering for fun and inflicting equivalent suffering as an unwanted by-product of some desired end. However, where that end is itself trivial, I suggest that the subjective feelings of the human agents involved are of rather less moment than those of the animals which actually experience pain or distress. Furthermore, this emphasis upon motivation is dangerous because there is unfortunately much evidence that very similar reasoning is frequently employed in situations where people are hurt. Industrialists who would not dream of physically abusing a child see nothing wrong in promoting bottle-feeding to mothers who lack facilities to use this method safely; babies die as a result, but the manufacturers feel no guilt because they were "only doing the best they could for their shareholders".

Finally, may I address your censure that animal rightists lack a sense of humour. I do not believe that those responsible for decisions which affect animals fully appreciate what very great distress is caused to many quite ordinary people by the infliction of suffering upon animals. Whether we like it or not, very large numbers of people do view their pets as members of the family, and react accordingly when similar animals are harmed. It is as unreasonable to expect them to keep, for example, the Draize test of shampoos, in proportion as it would be to expect an assault upon one child to be kept in proportion. When such people repeatedly' hear eminent scientists defending experiments which clearly are trivial, or saying that it is impossible to draw a line between cosmetic and medical experiments it is hardly surprising if they conclude that all animal experiments would prove equally unnecessary if closely investigated.

48 Gwydir Street,

ROSEMARY RODD

\section{Cambridge $C B I 2 L L, U K$}

SIR - The leading article on rights for animals contains several flaws. For example, you state that "there are simply no consistent or universal principles that imbue animals with 'rights' as exercised by humans". However, there is considerable controversy and disagreement among contemporary philosophers about the proper analysis of the notion of rights, human or animal. There is also heated disagreement about the proper substantive grounds for granting, or not granting, recognition of moral rights even to humans. Your justification for defending the rights of severely handicapped humans is purely consequentialist (once we curtail the rights of one group of humans, it will not be long before we curtail the rights of others). It could, therefore, be seen as a denial that such human beings have their own intrinsic moral rights.

One cannot, therefore, decide the issue of how animals should be considered merely by asserting that humans have moral rights that are different. We must, instead, squarely face the challenge laid down by several modern philosophers as to why humans and animals are treated so differently. In this regard, it is important to provide an adequate answer to why we should treat mentally incapacitated humans (who are apparently not rational nor self-aware) any differently from vertebrate animals which may be self-aware and capable of reason. Crook has recently discussed the concept of animal consciousness and has indicated that considerable moral implications stem from whatever conclusions are reached (J.H. Crook, Nature 303, 11-14; 1983).

It should also be noted that human recognition of "a moral obligation to treat animals with compassion and to respect their undeniable interests" is, at best, inconsistent and spotty. The pet dog and cat receive considerably more protection than the pig in a farrowing crate and yet surely pigs, dogs and cats have very similar mental capacities. The only reason that we can keep pigs in a manner not fit for a dog is because our interest in pigs is different from the interest in dogs. (In some societies, pigs are kept as pets and dogs eaten.) Our "respect" for the interests of the animals is primarily a concern for our own interests in the animal's well-being.

Obviously, we have to draw lines in establishing some form of moral construct for humans and the rest of creation. It seems intuitively obvious that bacteria do not and should not have the same moral status as ourselves but neither are they without any value whatsoever. However, it is equally obvious that we have not thought carefully about the place of mammals in the moral continuum and that there are many inconsistencies in our attitude towards and treatment of our fellow vertebrates.

ANDREW N. ROWAN

JERROLD TANNENBAUM

School of Veterinary Medicine,

Tufts University,

Medford, Massachusetts 02155, USA

\section{Israel squeezed in}

SIR - I was a little surprised to read in Nature (2 February, p.408) that Israeli scientists will not be able to participate in the 7th International Biotechnology Symposium. On the contrary, as the result of discussions and negotiations undertaken by the International Council of Scientific Union's Standing Committee on the Free Circulation of Scientists, arrangements were made for Israeli scientists to participate. Your correspondent received on 6 January a letter from the organizers advising him that his visa could be obtained on arrival. $\mathrm{He}$ also received a cable on 27 January informing him that Indian missions in Cairo, London and Rome had received cables giving instructions to clear his visa on application. It is easy to understand the concern of a scientist when having problems in obtaining a visa but to call for a boycott of the symposium when the person concerned knew that delicate negotiations were proceeding with the Indian authorities not only shows a singular disregard of the problems involved but is also unlikely to facilitate future negotiations, especially if the visa problem concerns the person involved.

Executive Secretary, F.W.G. BAKER

International Council of

Scientific Unions,

51 Bd de Montmorency,

75016 Paris, France 